University of Massachusetts Amherst

ScholarWorks@UMass Amherst

Economics Department Working Paper Series

Economics

2021

\title{
The Structural Outcomes of Investment Surges
}

\author{
Mateo Hoyos \\ University of Massachusetts at Amherst \\ Emiliano Libman \\ University of General San Martín \\ Arslan Razmi \\ Economics Department, University of Massachusetts Amherst
}

Follow this and additional works at: https://scholarworks.umass.edu/econ_workingpaper

Part of the Economics Commons

\section{Recommended Citation}

Hoyos, Mateo; Libman, Emiliano; and Razmi, Arslan, "The Structural Outcomes of Investment Surges" (2021). Economics Department Working Paper Series. 306.

https://doi.org/10.7275/22607583

This Article is brought to you for free and open access by the Economics at ScholarWorks@UMass Amherst. It has been accepted for inclusion in Economics Department Working Paper Series by an authorized administrator of ScholarWorks@UMass Amherst. For more information, please contact scholarworks@library.umass.edu. 


\title{
The Structural Outcomes of Investment Surges
}

\begin{abstract}
We study the extent to which countries undergo structural change during and after episodes of sustained investment surges. In particular, we explore the evolution of trade flows, considering (i) exports sophistication or complexity, (ii) exports diversification, and (iii) capital goods imports. Using the episodes identified by Libman et al. (2019), we document the heterogeneous nature of these episodes and find that, while imports of capital goods increase, they are not systematically related to changes in sophistication, complexity and diversification of exports, at least for the available sample of 130 episodes over the period 1962-2014. High investment may often be a necessary but not sufficient condition for structural change.
\end{abstract}

\author{
Mateo Hoyos* \\ Department of Economics \\ University of Massachusetts at Amherst \\ 106 Gordon Hall, Amherst, USA 01003 \\ Email: mhoyoslopez@umass.edu \\ Arslan Razmi \\ Department of Economics \\ University of Massachusetts at Amherst \\ 313 Crotty Hall, Amherst, USA 01003 \\ Email: arazmi@econs.umass.edu
}

\author{
Emiliano Libman \\ Business School \\ University of General San Martín \\ Caseros 2241, Buenos Aires, Argentina, 1650 \\ Email: elibman@unsam.edu.ar
}

JEL codes: E22, F41, O11.

Keywords: Capital accumulation, diversification, economic complexity, development.

\footnotetext{
* Corresponding author. This work was supported by the Chair's Summer Research Fund from the Department of Economics, University of Massachusetts, Amherst. Declarations of interest: none.
} 


\section{Introduction and Motivation}

Capital accumulation is typically seen as the key to growth and structural change. There are several potential mechanisms through which investment promotes growth, and the relative importance of these mechanisms is likely to vary with the nature of the economy, the starting income level of the country, and the sectoral allocation of capital. At low initial levels of income and small modern industrial sectors, economies are likely to benefit from the migration of labor from the low productivity traditional agrarian sectors to the higher productivity modern industrial sectors. At higher levels of income, other mechanisms such as internal and external economies of scale and learning externalities assume greater importance. Although structural change is normally equated to the movement of resources mainly from agriculture to manufacturing, in this paper we understand positive structural change as increases in sophistication, complexity and diversification of tradable activities. ${ }^{1}$ Regardless of the mechanism through which it promotes growth, economic diversification and structural change are often seen as both a cause and an outcome of capital accumulation. This makes sense in a development context. Private or public firms planning to enter new sectors often require capital investment to execute their plans. One would, therefore, expect to see investment surges to be followed by greater structural complexity in economies. This may, however, not always be the case. Consider, for example, an investment surge that follows a positive terms of trade shock for a primary commodity exporting economy. As documented by a large amount of literature on the Dutch disease issue, such a shock may then lead to further specialization in the commodity sectors experiencing the positive shock at the expense of other tradable goods-producing sectors. Alternatively, an initially labor-abundant country like South Korea that industrializes and evolves into a capital-abundant country may then specialize as it moves across cones of diversification and lose the older labor-intensive sectors. As is well-known, this latter

\footnotetext{
${ }^{1}$ In principle, we expect that structural change, as traditionally defined, may lead to increases in sophistication, complexity and diversification. Nevertheless, as they are not the same thing, this clarification is needed.
} 
possibility has been documented by Imbs and Wacziarg (2003) for economy-wide production structures, and by Cadot et. al. (2011), for the composition of exports.

We investigate how economies typically evolve during high investment episodes by taking advantage of 143 episodes of investment surges identified by Libman et. al. (2019). ${ }^{2} \mathrm{We}$ use the local projections method proposed by Jorda (2005) to explore the evolution of export diversification, sophistication and complexity during investment episodes. Our main statistically robust finding is that, consistent with the emphasis of much structuralist development literature, the composition of country imports shifts toward capital goods during investment episodes. For primary commodity exporters, episodes accompanied by rising terms of trade tend to lead to specialization while those accompanied by declining terms of trade lead to diversification. We also find that most episodes end with a higher proportion of medium- and high-tech products in total exports, and that for East and Southeast Asia, the export share of primary commodity exports declines (although it is small to begin with). However, we generally fail to find robust effects of investment surges on the degree of export sophistication and diversification. In addition, investment episodes do not seem to reliably affect the degree of economic complexity. This may be due to the low power of our tests and possibly because investment episodes have heterogeneous effects depending on the structure of the economy and the nature of the investment surge. Our analysis suggests that diversification and increase in complexity are likely to require innovative activities. High investment may constitute a necessary but not sufficient condition to enable such activities.

The next section carries out the econometric analysis, starting with a description of the data sources and methodologies employed. Section 3 compares our results with our a priori expectations. This inspires a closer look which we undertake in Section 4 with the help of a few country case studies. Section 5 concludes.

\footnotetext{
2 The number of episodes in the baseline specification of Libman et al. (2019) is 175, but trade flows data availability only allows us to study 143 of them, and even fewer when adding some control variables like the terms of trade.
} 


\section{Analysis}

As a basis for our analysis of the relationship between periods of high investment and structural change, we need to identify surges. We utilize the episodes of investment accelerations identified in an earlier study by Libman et. al. (2019). Inspired by Hausmann, Pritchett, \& Rodrik (2005), the baseline specification of that study specified the following three criteria to identify investment surges that lasted for a minimum of 8 years:

1. the annual per capita capital stock growth over an 8-year period must exceed 3.5 percent;

2. the annual per capita capital stock growth must have accelerated by at least 2 percentage points during the 8-year period; and

3. the level of capital per capita 8 years after the end of the acceleration episode must be above its historical peak.

The first criterion is meant to ensure that the capital stock per capita grows at a rapid rate while the second criterion ensures that the growth rate deviates significantly from the preepisode average. The third criterion helps avoid episodes that are pure recoveries from periods of capital stock destruction due to events such as civil wars and natural disasters. Following these criteria, the authors identify 175 episodes over the period 1950-2014 and an unconditional probability of occurrence of $2.1 \%$. The episodes are more likely to occur in middle-income countries, and the region with the highest number of episodes since 1960 is East Asia and Pacific, while the ones with the fewest are Europe and North America.

Having identified our investment accelerations, we next turn to formal econometric analysis and case studies to explore the evolution of our variables of interest during and after these episodes.

\subsection{Data Sources and Descriptive Statistics}

We mainly investigate the evolution of the export and import structure during and after the investment episodes. The analysis is based on some indicators (described below) built from trade data. The source of the data is the Atlas of Economic Complexity from Harvard University. The trade raw data come from COMTRADE but is then cleaned by researchers 
while compiling the Atlas to increase reliability. The export and import data are classified following the Standard International Trade Classification, revision 2, which allows us to have information for approximately 700 goods. Although there are classifications that allow us to have more disaggregated data (more products), the classification used provides the longest possible coverage in terms of years, which is crucial to analyze the majority of investment episodes identified by Libman et al. (2019). In particular, the trade data we use covers most of the countries in the world and spans the period 1962 to 2017.

The analysis uses three types of indicators based on trade data (Table 1 presents the precise definitions of the variables).

1. First, we use three indicators to measure the sophistication or complexity of exports. We use the technological categories proposed by Lall (2000), defined according to the $\mathrm{R} \& \mathrm{D}$ expenditures of each economic sector. To capture sophistication, we use the export share of medium and high-technology manufactures.

The second indicator we use to capture sophistication is the EXPY, as proposed by Hausmann, Hwang \& Rodrik (2007). The EXPY indicator is calculated as an average of the revealed measure of sophistication (associated income per capita) of each product a country is specialized in. ${ }^{3}$ A country exporting goods that are only exported by rich countries will have a high $E X P Y$ value.

Finally, we also use the Economic Complexity Index (ECI), as proposed by Hidalgo \& Hausmann (2009). The ECI index measures how diversified and complex the export basket of each country is. A complex product is one only exported by a few but highly diversified countries. A complex economy is one that is highly diversified and exporting products that only a few economies can produce (complex products).

\footnotetext{
${ }^{3}$ A country is specialized in a product if it exports the product with revealed comparative advantage.
} 
Table 1. Definition of the variables of the analysis

\begin{tabular}{|c|c|}
\hline Variables & Definition \\
\hline $\begin{array}{l}\text { Share of medium and high-tech } \\
\text { exports }\end{array}$ & $\begin{array}{l}\text { Using the taxonomy proposed by Lall (2000), each product is matched with one of the six technological } \\
\text { categories and then the shares of trade are obtained. Lall (2000) classifies goods in six categories: } \\
\text { commodities, natural resource-based manufactures, low-technology manufactures, medium-technology } \\
\text { manufactures, high-technology manufactures and other transactions. }\end{array}$ \\
\hline$E X P Y$ & $\begin{array}{l}\text { Following Hausmann et al. (2007), we first calculate the level of sophistication of each product } \\
(P R O D Y) \text {, as a weighted average of the GDP per capita of countries exporting it the weights being the } \\
\text { revealed comparative advantage figures). Second, we calculate the sophistication of each country } \\
(E X P Y) \text { as a weighted average (where the weights are simply the share of the product in exports) of the } \\
\text { PRODY of all the products a country's exports. }\end{array}$ \\
\hline$E C I$ & $\begin{array}{l}\text { We take the Economic Complexity Index (ECI) from the Atlas of Economic Complexity, calculated as } \\
\text { proposed originally by Hidalgo and Hausmann (2009). The authors use } 2 \text { measures to calculate the level } \\
\text { of complexity of a country's exports: first, diversification, i.e., the number of products the country is } \\
\text { specialized in (with revealed comparative advantage greater than 1), and, second, the ubiquity of a } \\
\text { product, i.e., the number of countries exporting it (with revealed comparative advantage greater than 1). }\end{array}$ \\
\hline Theil & $\begin{array}{l}\text { Following Cadot et al. (2011), we calculate the Theil index, used as a measure of redundancy or lack of } \\
\text { diversity. The Theil index is } 0 \text { when all products have the same share on the exports of a country } \\
\text { (interpreted as diversification), and } \log (\mathrm{N}) \text { when a country's exports is only one product (interpreted as } \\
\text { perfect specialization, } \mathrm{N} \text { being the number of products available). }\end{array}$ \\
\hline Gini & $\begin{array}{l}\text { Following Cadot et al. (2011), we calculate the Gini index of inequality where } 0 \text { represents perfect } \\
\text { equality of shares of exports (diversification) and } 1 \text { perfect inequality, or a product representing all } \\
\text { exports (specialization). }\end{array}$ \\
\hline HHI & $\begin{array}{l}\text { Following Cadot et al. (2011), we calculate the Herfindahl-Hirschman Index normalized between } 0 \text { and } \\
1 \text {, where } 0 \text { represents diversification in a sense of the share of exports being equal for all products, and } 1 \\
\text { when a country's exports is concentrated in only one product. }\end{array}$ \\
\hline Share of capital goods imports & $\begin{array}{l}\text { Using the Broad Economic Categories taxonomy, we classify each product according to their function } \\
\text { (consumption, intermediate or capital good), and then calculate the shares using import data. }\end{array}$ \\
\hline
\end{tabular}


2. The second set of indicators used in the analysis incorporates diversification of exports directly. Following Cadot, Carrere, \& Strauss-Kahn (2011), we use the trade data from the Atlas of Economic Complexity to calculate three indicators of concentration of exports: the Theil, the Gini, and the Herfindahl Hirschcman Index (HHI).

3. The final set of indicators we use are those applied to import data. First, based on the Broad Economic Categories (BEC) classification, we calculate the share of imports of capital goods to study its evolution during and after the investment episodes. Second, we also calculate the Theil, Gini and $H H I$ indices to evaluate the evolution of concentration of imports during and after investment episodes.

Table 2 provides some summary statistics for these variables which are often employed in the trade and development literature. We now proceed to discuss some of their characteristics and show their relevance for the analysis of development problems.

Table 2. Descriptive Statistics: 238 countries, 1962-2017

\begin{tabular}{lccccccc}
\hline Variables & Obs. & Mean & $\begin{array}{c}\text { St. } \\
\text { Dev. }\end{array}$ & Min & Max & p1 & p99 \\
\hline $\begin{array}{l}\text { Share of medium and } \\
\text { high-tech exports }\end{array}$ & 11512 & 0.190 & 0.218 & 0.000 & 1.000 & 0.000 & 0.840 \\
EXPY & 11512 & 12627 & 4603 & 2632 & 27308 & 3700 & 21281 \\
ECI & 11520 & 0.036 & 0.970 & -4.465 & 3.321 & -2.052 & 2.201 \\
Theil & 11426 & 2.865 & 1.099 & 0.000 & 6.195 & 0.810 & 5.483 \\
Gini & 11426 & 0.907 & 0.084 & 0.049 & 0.997 & 0.637 & 0.994 \\
$H H I$ & 11426 & 0.217 & 0.219 & 0.000 & 0.998 & 0.007 & 0.890 \\
Share of capital goods & 11468 & 0.191 & 0.115 & 0.000 & 0.998 & 0.019 & 0.747 \\
imports & 11453 & 1.700 & 0.700 & 0.127 & 5.923 & 0.858 & 4.663 \\
Theil imports & 11453 & 0.795 & 0.065 & 0.286 & 0.996 & 0.629 & 0.967 \\
Gini imports & 11453 & 0.052 & 0.102 & 0.003 & 0.944 & 0.006 & 0.590 \\
HHI imports & \multicolumn{7}{c}{ Source: author's elaboration based on by the Atlas of Complexity (2019). }
\end{tabular}

Figure 1 shows a scatterplot of EXPY against the GDP per capita for 2003. As expected, the correlation between the two is positive and significant. This means that rich (poor) countries tend to export products that other rich (poor) countries also export. Table 3 shows the five less and most sophisticated countries according to the EXPY in 2003. The less 
sophisticated economies are all low-income countries in Africa while the most sophisticated economies are mainly European and Asian. These results coincide with those reported by Hausmann et al. (2007).

Figure 1. Relationship between EXPY and GDP per capita, 2003

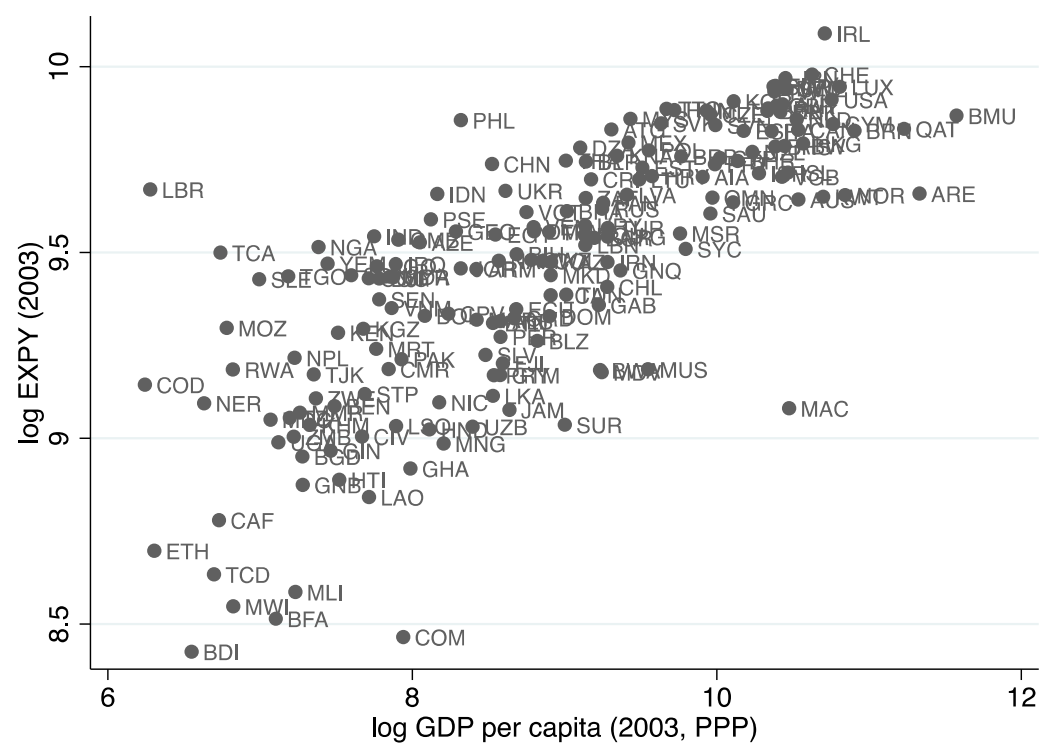

Source: authors' elaboration based on data by the Atlas of Complexity (2019).

Table 3. Countries with the lowest and highest EXPYs, 2003

\begin{tabular}{clcllc}
\hline & Country & EXPY & Country & EXPY \\
\hline Smallest & Burundi & 4562.8 & Largest & Ireland & 24086.7 \\
& Comoros & 4746.9 & & Switzerland & 21558.5 \\
& Burkina & 4986.8 & Japan & 21352.8 \\
& Faso & 5155.1 & Finland & 20915.4 \\
& Malawi & 5359.0 & Singapore & 20882.7 \\
\hline
\end{tabular}

Source: authors' elaboration based on data by the Atlas of Complexity (2019).

Figure 2 reveals the relationship between ECI and GDP per capita for the same year, 2003. The correlation is positive as expected and significant. This means that rich countries tend to be diversified and export complex products that only a few diversified economies also export. Table 4 reveals the less and most complex economies in 2003. Consistent with our previous findings using EXPY, the less complex economies are mostly African, while the most complex economies are European countries and Japan. 
Figure 2. Relationship between $E C I$ and GDP per capita

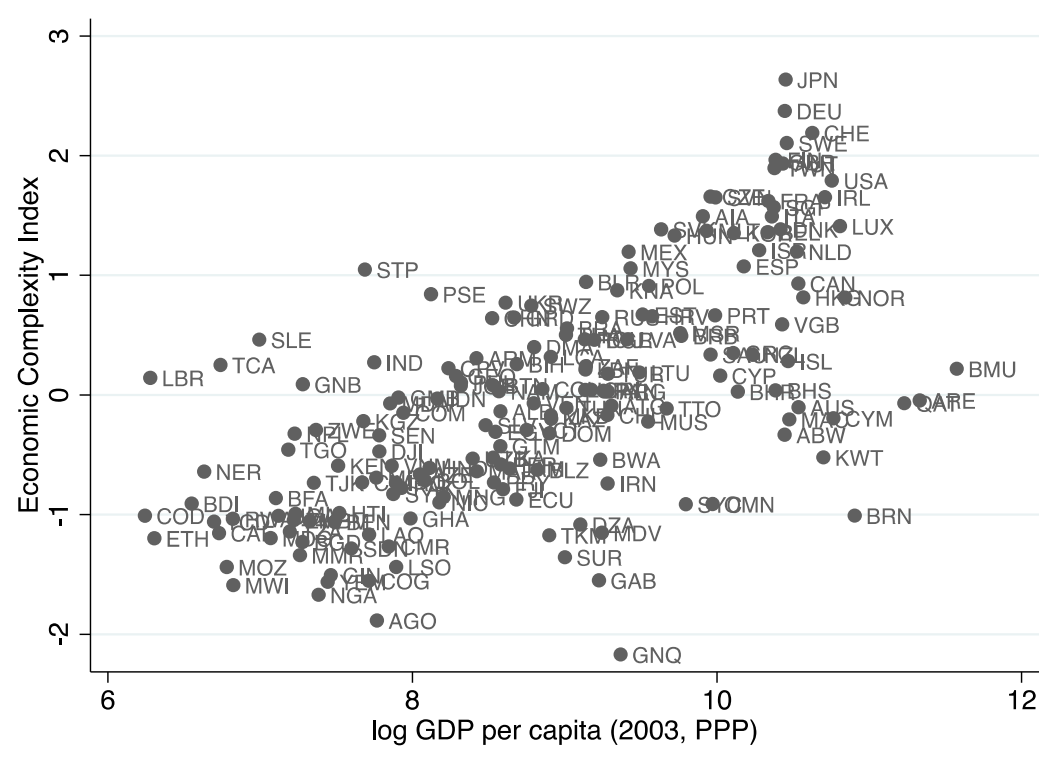

Source: authors' elaboration based on data by the Atlas of Complexity (2019).

Table 4. Countries with lowest and highest ECI, 2003

\begin{tabular}{|c|c|c|c|c|c|}
\hline & Country & $E C I$ & & Country & $E C I$ \\
\hline \multirow[t]{5}{*}{ Smallest } & $\begin{array}{l}\text { Equatorial } \\
\text { Guinea }\end{array}$ & -2.17 & Largest & Japan & 2.64 \\
\hline & Angola & -1.88 & & Germany & 2.37 \\
\hline & Nigeria & -1.67 & & Switzerland & 2.19 \\
\hline & Malawi & -1.59 & & Sweden & 2.11 \\
\hline & Yemen & -1.56 & & Finland & 1.97 \\
\hline
\end{tabular}

Source: authors' elaboration based on data by the Atlas of Complexity (2019).

We now turn to the indices of export concentration. According to Imbs and Wacziarg (2003) and Cadot et al. (2011), the relationship between diversification and development follows a hump- or inverted U-shaped form: countries at lower levels of income tend to be specialized in a few products. As they develop, they become more diversified up to a point after which they start to specialize again. As seen in Figure 3, we find a similar pattern. Moreover, our turning point in the relationship, approximately equal to the income per capita of Ireland in 1996, coincides with the one reported by the above-cited studies. The graphs using Gini and $H H I$ look pretty much the same. 
Figure 3. Predicted relationship between Theil index and number of exported products with GDP per capita

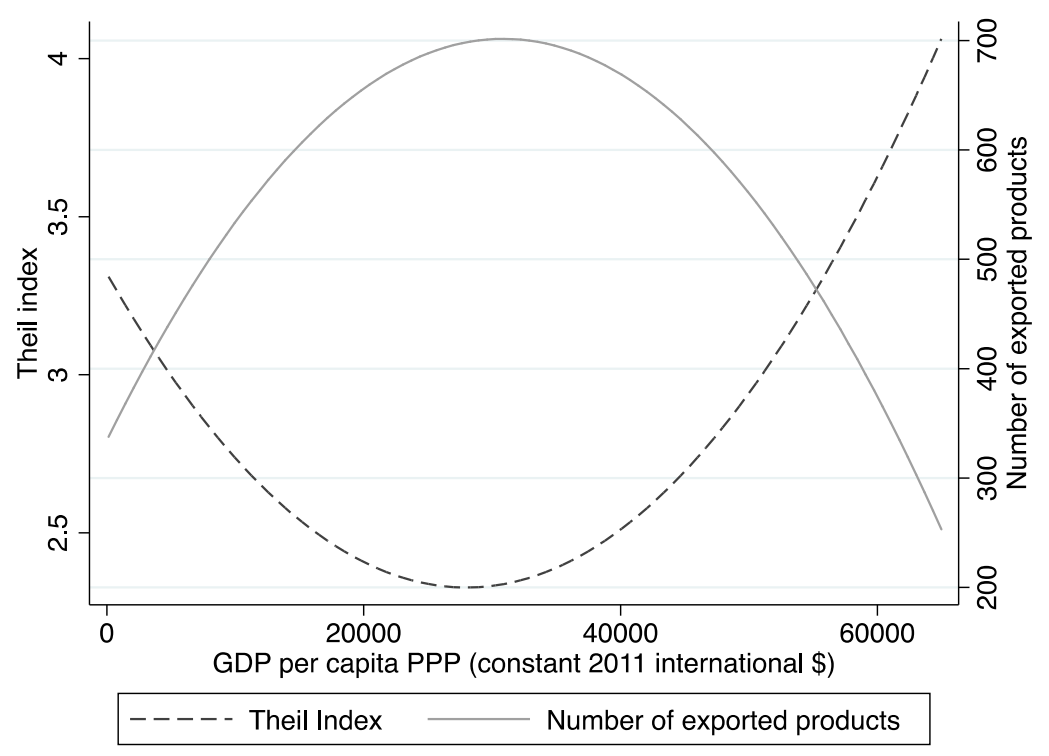

Source: authors' elaboration based on data by the Atlas of Complexity (2019).

According to Libman, et. al. (2019), investment surges are more likely at low- and middleincome levels. The unconditional probability of an investment episode taking place varies between $2.5 \%$ and $3.4 \%$ for the first four quantiles (with average incomes per capita of $1262,2611,5,959$ and 12,194 constant international US\$), while it is only $0.9 \%$ for those in the uppermost quintile (with an average income per capita of 34,556 constant international US\$). The turning point in Figure 3 coincides with the average income of those countries where an investment episode is the least likely to take place (abstracting from the influence of other confounding variables) Hence, the combined evidence suggests that on average, countries that are in the diversification zone are also more likely to experience capital accumulation and growth at fast pace.

\subsection{Econometric Approach}

Next, we explore more formally the relationship between investment acceleration episodes and various measures of trade-related structural change. We use the method of local projections as proposed by Jordà (2005) to evaluate the evolution of the trade indicators 
already described. The method consists of estimating local projections (regressions) at each period of interest, in this case the years of the episode and some years after. We run at each point of interest a two-way fixed effects regression to adjust for unobserved countryspecific and year-specific confounders at the same time. The simple OLS regression calculated at each point of interest has the following form:

$$
y_{i, t+h}=\alpha+\beta_{h} \text { Episode }_{i, t}+\gamma_{h} G D P P C_{i t}+f_{t}+f_{i}+u_{i t}
$$

where $y_{i, t+h}$ represents the cumulative change in each of the trade indicators at the year $h$, $f_{t}$ represents time fixed effects, $f_{i}$ represents country fixed effects, GDPPC $C_{i t}$ represents the GDP per capita, and Episode $e_{i, t}$ is a dummy for the year of start of investment episodes.

The cumulative change is calculated with respect to four years before the episode, to avoid capturing pre-existing trends. Additionally, in the baseline setting we also include three years after the end of the episode to be able to see trends after the end of the episode. In other words, the equation is estimated for $h=-3,-2, \ldots, 0,1,2 \ldots, 9,10$. The variable of interest is the dummy of the investment episode, meaning the coefficient of interest is $\beta_{h}$, capturing differences in the evolution of each of the trade indicators during episodes compared to normal times.

\subsection{A Priori Expectations}

Traditionally, development theory has emphasized that the process of capital accumulation in developing countries involves, to a large extent, the mobilization of resources from the traditional to the modern sector, which has a higher level of labor productivity and is the locus of technical progress. As capital accumulates and a large share of the labor force is re-allocated, income per capita increases (see Ros, 2013, specially chapters 7 and 8). While the connection between the structure of domestic production and the composition of foreign trade during the process of economic development is not clear-cut, it seems plausible to expect certain changes in the type of goods that are exported and imported during a typical episode. Let's consider some specific indicators. 
Diversification and sophistication of exports: The relationship between income per capita and the degree of diversification of production is likely non-linear. Following Imbs and Wacziarg (2003) and Cadot et al. (2011), the degree of diversification seems to follow a U-shaped pattern. Production first diversifies, but late in the development process there is re-specialization again. Although the volume of exports depends on the dynamics of production and domestic absorption, one would therefore expect the degree of diversification of exports to depend on the level of income per capita at the beginning of the investment surge. However, as the large share of the episodes in our sample takes place at low- or middle-income levels, countries are typically below their diversification peak, and thus we are more likely to observe an increase in diversification during episodes. Iacovone and Javorcik (2008), for example, find that export diversification in Mexico is preceded by a rise in firm investment.

The degree of sophistication of the export basket, measured for example by the proportion of high-tech exports, or the shares of homogeneous goods and of differentiated goods, may also change during the process of economic development and consequently during episodes. Some empirical findings suggest that countries that produce and export more sophisticated goods tend to grow faster (Hausmann et. al., 2006), and fast-growing economies also exhibit a large number of episodes. To export complex goods, a strong modern sector that employs highly qualified workers and adopts cutting-edge technologies is likely required. Because the expansion of the modern sector is an important engine of economic development, it is plausible to observe a positive correlation between export complexity (or its change) and economic growth.

Composition of Imports: Episodes often take place in low- and middle-income countries and production in their modern sectors often requires imported intermediate inputs and capital goods that are hard to substitute with local production. During a typical episode it is plausible to expect a noticeable increase in imports of intermediate inputs and capital goods, especially in those episodes where manufactures are the main driver of growth. In contrast, episodes triggered by the expansion of natural resource intensive sectors may exhibit a lower dependency on specific imported intermediate inputs and capital goods. 
Manufactured vs. Natural-Resource Based Episodes. More complex (and diversified) export baskets provide a steadier stream of foreign exchange, contributing to a more robust balance of payments position. Exports of simpler goods can also help to relax the external constraint, but their prices are usually more volatile and constitute a less reliable source of foreign exchange. International capital markets are far from perfect and they usually cannot be tapped for funds when most needed, as eagerness to lend goes hand in hand with the prices of commodities (Kaminsky et. al., 2004).

While countries may be able to cushion the effects of volatile terms of trade and capital flows, for instance, by the adoption of appropriate macroeconomic policies, low- and middle-income country typically have less room to implement countercyclical policies. It is thus not surprising that, barring some exceptions, exporters of homogeneous commodities display slow growth subject to frequent interruptions and experience a smaller number of episodes. However, it is still possible to identify many episodes that are either triggered by an increase in the price of a natural resource or a large inflow of capital. In those episodes, complex and diversified manufacturing sectors can be hurt by the high relative price of non-tradable goods, reducing the diversification and the complexity of the export basket. Likewise, the composition of imports may react differently, depending on whether manufactures or natural-resources or services are the main drivers of the episode, as the former are highly dependent on specific imported inputs.

Short/Long Episodes \& Low/High Growth Episodes. The sustainability of an investment episode may depend on the evolution of consumption and investment, and thus the composition of imports may also vary according to the duration of an episode or the speed at which capital accumulates. For instance, episodes that are long and/or exhibit a high rate of growth may deliver a stronger increase in the imports of investment goods (compared to consumption goods) than episodes that are short and/or where the rate of growth is low.

\subsection{Econometric results}

Our analysis proceeds in two steps, beginning with some less formal statistics and then providing the results of the local projections described earlier. 
Starting with some simple diagnostics, we classify the episodes according to the average change in the main indicators of interest during and after the investment episodes. We first calculate the average value of each variable for the 10 years after the start of the episode and compare it to the average value for the 5 years before the start of the episode. Table 5 presents these calculations and provides some preliminary answers.

Table 5. Structural change during investment episodes

\begin{tabular}{lcccc}
\hline & Diversification & Specialization & No change & Total \\
\hline Increasing Complexity & 36 & 30 & 0 & $\mathbf{6 6}$ \\
Declining Complexity & 23 & 53 & 1 & $\mathbf{7 7}$ \\
No change & 0 & 0 & 0 & $\mathbf{0}$ \\
& & & & $\mathbf{9 6}$ \\
Increasing Sophistication & 46 & 50 & 0 & $\mathbf{4 5}$ \\
Declining Sophistication & 12 & 32 & 1 & $\mathbf{2}$ \\
No change & 1 & 1 & 0 & $\mathbf{9 3}$ \\
Increased proportion of medium and & 47 & 46 & 0 & $\mathbf{3 8}$ \\
high-tech products in total exports & & & 1 & $\mathbf{1 2}$ \\
Reduced proportion of medium and & 9 & 28 & 0 & $\mathbf{1 4 3}$ \\
high-tech products in total exports & 3 & 9 & $\mathbf{1}$ \\
No change & & $\mathbf{8 3}$ & & \\
Total & $\mathbf{5 9}$ & & & \\
\end{tabular}
Source: authors' elaboration based on data by the Atlas of Complexity (2019).

Consider first the number of episodes that led to both increased complexity and diversification. This number is 36 , or about a quarter of the total number of cases (i.e., 143). The first result, therefore, that seems surprising is that most of the episodes (83) result in an increased specialization of the export basket. It is also surprising that most of the episodes (77) result in declining complexity. Using the sophistication indicator by (EXPY), on the other hand, reveals that most of the episodes (96) deliver increasing sophistication. As we see below, this may be true regardless of whether or not the countries experience rapid investment during their growth process. Finally, consistent with our expectations, an overwhelming number of countries (93) experience an increase in the share of mediumand high-tech exports in their baskets at the end of investment episodes and only 38 experience a decline. However, a higher share of medium- and high-tech products does not 
seem to go hand in hand with diversification and is in fact equally likely to coexist with specialization (there are 47 cases of diversification and 46 of specialization). This contrasts with the case of increasing (falling) complexity which is more likely to be associated with diversification (specialization).

The structure of trade may be important for explaining the previous results. Thus, using simple diagnostics again, we add to the analysis the evolution of terms of trade and the share of exports of commodities, and we focus our attention on changes in complexity and diversification. We divide episodes taking into account the share of exports of commodities at the beginning of the episode: the threshold to divide them is $33 \%$ (a higher share means the country is a commodity exporter). Table 6 presents the main results of this additional exercise.

Table 6. Investment episodes according to the sector of exports and terms of trade

\begin{tabular}{lcccccc} 
& \multicolumn{2}{c}{ Manufacturing exporters } & & \multicolumn{2}{c}{ Commodity exporters } \\
\cline { 2 - 3 } \cline { 5 - 6 } & TOT up & TOT down & & TOT up & TOT down \\
\hline Diversification & 10 & 12 & & 8 & 22 \\
Specialization & 12 & 17 & & 24 & 11 \\
\hline Increasing complexity & 15 & 15 & & 14 & 17 \\
Decreasing complexity & 7 & 14 & & 18 & 16 \\
\hline
\end{tabular}

Source: authors' elaboration based on data by the Atlas of Complexity (2019) and data on terms of trade from the IMF (2019). Note: TOT means terms of trade.

The majority of episodes in manufacturing exporters (30 out 51) show increased complexity, regardless of the evolution of terms of trade. There is no clear pattern of relationship between terms of trade, episodes and changes in complexity in commodity exporters. Now consider changes in diversification. A slightly higher proportion of episodes in manufacturing exporters tend to lead to specialization of exports, regardless of what happens to the terms of trade. An interesting pattern arises when we analyze diversification for commodity exporters during investment episodes. If the terms of trade for a commodity exporter are going down (up), an investment episode tends to lead to diversification (specialization). This exercise suggests that the impact of investment episodes on structural change patterns may be mediated by terms of trade and its interaction 
with the main sector of the exports of a country. We formally control below for these variables (terms of trade and share of commodity exports) and their interaction in our more formal exercise below.

Our simple diagnostics do not show how the indicators behave in comparison to normal times (when episodes are not occurring). To evaluate, in a more precise way, the evolution of trade flows during investment episodes we proceed to the analysis using the local projections method.

\section{Local Projections}

The main results of the local projections, described earlier in section 2.2, are presented in Figure 4. The red lines represent the beginning and the end of an investment episode, while the light grey and dark grey areas represent the 95 and 90 confidence bands respectively.

Two main lessons can be derived. On the one hand, the results suggest that there are no clear trends in complexity, sophistication, and diversification of exports during the episodes. There are also no clear trends in import diversification. On the other hand, the result show that there is a statistically significant increase in the share of capital goods imports in the first three years of the episode and a reduction in the share of consumption goods imports, considering the episode as a whole. ${ }^{4}$ As mentioned before, we also ran projections including the terms of trade, the share of commodity exports and their interaction, to account for the influence of the structure of the economy on the impact of the episodes, and the squared GDP per capita to account for the U-shaped relation between diversification and development. Since the results are qualitatively similar we only show in Figure 4 the results following the specification presented in section 2.2. The entire results are available as an appendix and upon request.

\footnotetext{
${ }^{4}$ In projections for countries where exports of commodities are more than $33 \%$ at the beginning of the episode the impact on capital goods imports almost disappears. Only in the first year of the episodes we observe a significant increase in imports of capital goods. That implies that the increase in capital goods is driven principally by the investment episodes in countries where exports of manufactures are more important.
} 
Figure 4. Complexity, sophistication, diversification and composition of imports before, during and after investment episodes.
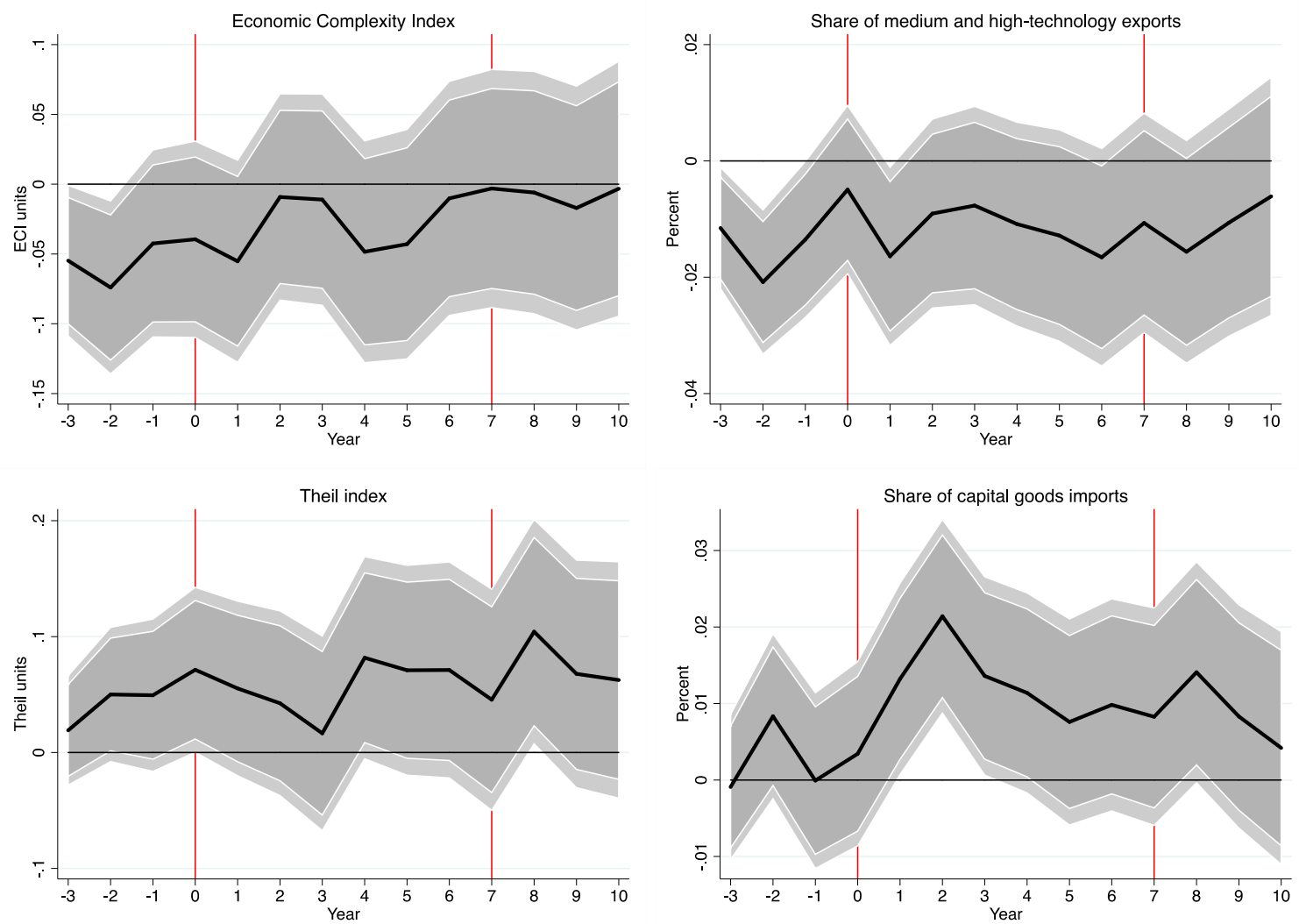

Source: authors' elaboration based on data by the Atlas of Complexity (2019). Note: These graphs represent the outcome of the coefficient $\beta_{h}$ from the equation in section 2.2 for each $h$.

Next, we explored how robust the results are to different samples and episode types. For instance, when we restrict the sample by region, the main differences are as follows. In Southern Europe there is an increase in sophistication (EXPY) and in complexity in the last year of the episode and one after, but these results do not hold for exports of medium and high-tech goods. In South-eastern Asia there is an increase in capital goods imports during the first half of the episode and by the end. In Northern Europe there is an increase in specialization during the episode using the Gini and the Theil indexes, a decrease in the share of medium and high-tech exports together (but not in high-tech only). In Latin America, there is a decrease in complexity in the first year of the episode and an increase in specialization at the end of the episode using Gini and Theil index. Finally, In Africa, Southern Europe, Northern Europe, Eastern Europe, Western Europe and Eastern Asia, 
there is no increase in the share of capital goods imports. Most results do not depend on the level of income, except that there is a significant increase in specialization using Gini in low income countries.

Following Libman et. al. (2019), we also considered three different types of episodes that are of interest for our purposes: (1) Tradable episodes, (2) Sustained episodes, and (3) Manufacturing episodes. For (1) we separate episodes associated with investment booms in non-tradables from those in tradables, using data on capital accumulation in the construction sector and the machinery and equipment sector, respectively. Applying the filter to the disaggregated capital stock series, we identify 147 episodes for non-tradable booms and 268 episodes of tradable booms. For (2) we identify as "sustained" those episodes where capital per person growth is at least 3.5 per cent in the 8 -year window following the episode. According to this refined criterion, about half of the original episodes (85 out of 175) are classified as sustained. For (3), we combine information from the WDI on the manufacturing share of total value added and the manufacturing share of total exports for each country. When both the value added and the export shares for a country are larger than the world average for more than half of the sample period, we classify that country as a manufacturing one for the entire sample. The rest of the countries are de facto considered non-manufacturing producers, even if there are no WDI data for them. ${ }^{5}$ The reasons to dig more deeply are, as discussed earlier in section 2, closely related to the special role that manufactures and tradable activities play in the process of development, and the stop-go nature of economic growth associated with improved terms of trade and capital flows bonanzas.

Considering tradable episodes only (which are those where the surge in investment takes place in machinery and equipment), we find that they end with specialization using $H H I$

\footnotetext{
${ }^{5}$ When very little data are available, we only consider the longer series. When no data exist that country is excluded, except a well-known example: there is no data for Taiwan, but we include it in the group of manufacturing countries. The full list of manufacturing countries includes: Argentina, Bolivia, Brazil, Botswana, Chile, China, Colombia, Costa Rica, Denmark, Egypt, Ethiopia, France, Germany, Ghana, Hong Kong, India, Indonesia, Italy, Japan, Kenya, South Korea, Malawi, Malaysia, Mauritius, Mexico, Morocco, Netherlands, Nigeria, Peru, Philippines, Senegal, Singapore, Spain, Sweden, Taiwan, Tan- zania, Thailand, United Kingdom, United States, and Venezuela. The rest is considered as non- manufacturing.
} 
and Theil, and there is an increase in capital goods imports which is associated mainly with electric machinery. In contrast, when we consider non-tradable episodes, specialization in exports precede the episodes and there is a slight increase in the share of capital goods imports during the episode. There appears to be an increase in the share of high-tech exports after the end of typical episodes. On the other hand, if we consider 5-year episodes, we find that high-tech exports increase 10 years after end of the episode, the share of capital goods imports increases during the whole episode and after 5 years of the end, both the shares of imports of intermediate and consumption goods decrease during the episode.

For sustained episodes (those where growth remains at 3.5 percent in per capita terms, once the episode ends), there is a decrease in sophistication during the episode, an increase in specialization using Gini and Theil index, a significant fall in the share of medium and high-tech exports during and after the episode, and an increase in capital goods imports. For episodes that are constructed using a 5-year window, there is an increase in the share of high-tech exports in year 2 of the episode and an increase in the share of capital goods imports. Using a 9-year window there is also an increase in capital goods imports, while if we use a 12-year window there is no clear difference with respect to the baseline specification.

If we consider episodes where the share of manufacturing employment increases more than the median change during the episode, there is an increase in complexity during the first two years of the episode and an increase in diversification in the first year of the episode with the Gini. When we restrict the episodes to last only 5 years, we find that complexity increases one year before the episode until the second year, and that there is an increase in diversification using Gini and Theil index and an increase in capital goods imports by the end of the episode. We should notice that due to data limitation, only a small share of episodes was classified as "manufacturing” (44 out of a total of 203 episodes).

In sum, the local projections suggest three statistically significant and relatively robust results: (1) capital goods imports as a proportion of total imports increase (and consumption goods decline) during episodes, (2) most episodes end with a higher proportion of mediumand high-tech products in total exports, and (3) distinguishing countries by region, in East 
and Southeast Asian economies the share of primary commodity exports declines during episodes (although it is small to begin with).

\section{A Discussion of the Match between Expectations and Results}

Several of the results are not in line with our expectations and some of them are not entirely robust. This is particularly true for those results related to the dynamic of exports. For example, we do not find a statistically significant increase in diversification or economic complexity during investment episodes. In contrast, the results associated with the dynamics of imports confirm our priors. The overall picture thus suggests that there are few changes in terms of diversification or sophistication of foreign trade during and after investment episodes, while there is a clear connection between capital accumulation and imports of capital goods. This suggests that during a typical episode, foreign trade seems to experience little structural change, as the export basket does not become more complex and diversified, and the dependence of certain foreign inputs remains strong.

Let us consider some of the results in detail. There is no clear indication that investment episodes are associated with significant changes in export diversification or complexity, even if we consider different type of episodes, windows and groups of countries. Moreover, in some instances there is a decrease in complexity in the first year of the episode and an increase in specialization at the end, for example in Latin America. This may suggest that some episodes can be associated with natural resources discoveries, improvements of the terms of trade or capital flow bonanzas. However, in the East Asian and South Asian cases there are no clear indications that during episodes the countries experience significant changes in the complexity or diversity of their export baskets. In the same vein, considering episodes where the share of manufacturing employment increases more than the median change during the episode, there is a mild increase in complexity and diversification during the first years of an episode only. A similar lesson follows when we analyze tradable episodes.

When we compare tradable vs. non-tradable episodes, we find no clear differences in terms of changes in diversification and sophistication of the export baskets; in other words, 
during both type of episodes there are no clear trends. There is a slight difference: the reactions of imports of capital goods is somewhat weaker in the non-tradable case. This is what we should expect if tradable activities are those associated with complex input-output relations that imply low substitutability, while the non-tradable activities involve fewer imported goods. Notice that increases in the capital stock associated with construction, which is a non-tradable activity almost by definition, is precisely the variable that defines the non-tradable nature of an episode. ${ }^{6}$

Regarding the sensitivity of the results with respect to changes in the time window, we did not find any consistent pattern either. For instance, if we consider longer windows for tradable episodes, there seems to be an increase in the share of high-tech exports some years after the end of the episode, which suggests that changing the export basket requires a span of time that exceeds the typical episode. However, when we considered sustained episodes, there is a decrease in sophistication during the episode, an increase in specialization using Gini and Theil index, and a significant fall in the share of medium and high-tech exports during and after the episode. Thus, the evidence that we were able to gather does not suggest the presence of clear trends that affect the composition of the export baskets.

Moving to the import side, the results clearly suggest that investment surges are associated with increases in the share of imports of capital goods during the first part of an episode, and a reduction of the share of consumption goods. This result is what we should expect, considering that most episodes take place in low- and middle-income countries, which are typically highly dependent on imports of specific goods in order to carry on regular

\footnotetext{
${ }^{6}$ It is important to keep in mind that in some particular instances, manufacturing activities are non-tradable due to the presence of tariff and other barriers to trade. Thus, we cannot exclude the possibility that some of the episodes classified as non-tradable are heavily dependent on imported inputs. However, this concern is somewhat weakened because our dataset spans a period of time that starts in 1950. After the end of the $2^{\text {nd }}$ World War, the increase in trade openness, associated with the emergence of global value chains and the progressive reduction in barriers to trade, may have significantly reduced the number of episodes where nontradable manufacturing activities are the main driver of growth.
} 
production. This is a robust result that holds regardless of the region, the type of episode and the size of the window considered.

In some cases, the increase in capital goods imports is driven by specific groups of goods, such as electric machinery, telecommunications and specialized capital goods, but there is no clear additional pattern, other than the close connection between sustained surges in investment and large increases in imports of capital goods and other intermediated inputs. The fact that we get few statistically robust results in line with our expectations from economic theory raises several possibilities. First, that there are no statistical relationships to be found, which may in turn suggest that diversification and sophistication may require not only investment but also innovative activities, among other things. This theoretical possibility is one of the main tenets of evolutionary literature on catching up growth and development (Perilla-Jimenez, 2019). A second possibility is that the low statistical power of our tests due to the limited number of investment episodes available does not allow us to capture the expected results. Third, that the direction of change in economic structure may vary with the factors that lead to an investment episode. For example, in some cases, a positive terms of trade shock that causes investment in the export sector of a primary commodity exporting economy is likely to be accompanied by specialization rather than diversification. And finally, consistent with Imbs and Warciarg (2003) and Cadot, et. al. (2011), accelerated investment may be accompanied by diversification at lower levels of income but specialization at higher levels. While our limited sample size does not allow us to formally investigate these alternative explanations, the next section briefly turns to a few country case studies to take a closer look.

\section{A Few Case Studies for Illumination}

Let's briefly investigate a sample of factors that may influence the trajectory of structural change during episodes of accelerated investment. We chose 5 countries - Indonesia, South Korea, Peru, Turkey, and Uganda -- with the following considerations in mind: (1) to enable within country comparison across time, the economies must have experienced more than one investment episode, (2) geographic diversity, (3) different initial starting 
conditions in term of economic structure (e.g., primary exporters versus manufacturing exporters).

We briefly discuss each country and then summarize a few broad lessons. Table 7 provides the summary statistics underlying our analysis.

\section{South Korea}

South Korea experienced three investment episodes beginning in 1962, 1972, and 1988. The first episode, coinciding with the first five-year plan (1962-67), occurred at an extremely low level of initial income (\$976 in 2010 constant US dollars) and converted Korea into a manufacturing exporter. Starting at 18 percent the manufacturing share of exports increased by 65.4 percentage points during the episode. The second episode, overlapping with the beginning of the "Heavy-Chemical Industry Drive," began when the share of manufacturing in exports was already very high at almost $84 \%$, and resulted in more diversification and a larger shift of 19.5 percentage points toward medium- and hightech exports.

The first two episodes, which happened during times of declining or stable terms of trade led to diversification. The Theil index fell by 0.2 points during each episode, which is a major change considering that Korea's Theil index started at 1.9 in 1962 and ended at 2.3 in 2019. The third episode, which started when Korea was a middle-income country, and had an even higher level of manufactures' share of exports, occurred during a period of rising terms of trade. Although this episode did lead to a large increase in EXPY and another dramatic increase in the share of medium- and high-tech exports, but it was accompanied by specialization (the Theil index increased by 0.2 points), and a small decline in the overall share of manufactures in exports. While the level of income at which this change occurred is lower than the global threshold identified by Cadot et. al. (2011), it is consistent with the overall story of initial diversification followed later by specialization. 
Table 7. Structural changes in countries experiencing multiple episodes

\begin{tabular}{|c|c|c|c|c|c|c|c|c|c|c|}
\hline & $\begin{array}{c}\text { Begin } \\
\text { year }\end{array}$ & $\begin{array}{l}\text { GDP (constant } \\
2010 \text { US dollars) }\end{array}$ & Initial_Man_X & $\triangle T O T$ & $\Delta$ Man_X & $\Delta M T \_H T$ & $\Delta M a n \_M$ & $\triangle E C I$ & $\triangle E X P Y$ & $\Delta$ Theil \\
\hline \multirow[t]{3}{*}{ Korea } & $1962^{a}$ & 976 & 18.2 & 1.46 & 62.4 & 14.0 & 2.09 & 0.4 & 1496 & -0.2 \\
\hline & 1972 & 2,045 & 83.6 & -35.3 & 11.1 & 19.5 & -10.4 & 0.1 & 2529 & -0.2 \\
\hline & 1988 & 7,365 & 93.1 & 17.0 & -0.3 & 18.6 & 2.7 & 0.1 & 2714 & 0.2 \\
\hline \multirow[t]{3}{*}{ Indonesia } & 1970 & 737 & 1.2 & 17.5 & $1.2^{\mathrm{b}}$ & 0.4 & $-13.7^{\mathrm{b}}$ & -0.4 & 3264 & 0.9 \\
\hline & 1990 & 1,708 & 35.5 & -5.8 & 23.3 & 18.7 & -12.2 & 0.6 & 1805 & -1.3 \\
\hline & 2005 & 2,524 & 47.2 & 16.3 & -11.2 & -5.8 & 4.5 & 0.1 & -1076 & 0.1 \\
\hline \multirow[t]{2}{*}{ Peru } & 1993 & 2,673 & 16.9 & 2.4 & 5.1 & 0.0 & 5.0 & -0.2 & 157 & -0.1 \\
\hline & 2004 & 3,603 & 19.2 & 47.5 & -5.9 & 4.0 & 4.3 & 0.1 & 409 & 0.2 \\
\hline \multirow[t]{3}{*}{ Turkey } & $1964^{\mathrm{b}}$ & 3542 & 8.9 & n.a. & 5.3 & 1.3 & 2.2 & 0.3 & 853 & 0.0 \\
\hline & 1983 & 5310 & 67.9 & 8.7 & 23.7 & 7.6 & 13.8 & -0.2 & 1072 & -0.3 \\
\hline & 2003 & 8331 & 83.7 & -9.3 & -3.0 & 4.0 & -5.2 & -0.1 & 1618 & -0.1 \\
\hline \multirow[t]{3}{*}{ Uganda } & $1965^{c}$ & n.a. & 0.4 & n.a. & n.a. & 0.0 & n.a. & 0.0 & -252 & 0.5 \\
\hline & 1995 & 474 & 4.4 & -15.1 & -2.2 & 4.8 & -6.7 & 0.5 & 3837 & -1.1 \\
\hline & 2003 & 608 & 11.7 & 6.0 & 18.1 & 9.5 & -2.3 & 0.6 & 1225 & -0.4 \\
\hline
\end{tabular}

Source: authors' elaboration based on data by the Atlas of Complexity (2019) and data on terms of trade from the IMF (2019).

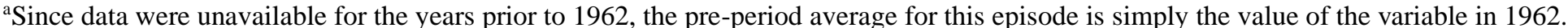

bince data were unavailable for the years prior to 1970, the pre-period average for this episode is simply the value of the variable in 1970.

${ }^{\mathrm{c}}$ Since data were unavailable for the years prior to 1970, the initial value for this episode is simply the value of the variable in 1976.

Initial_Man_X: Manufacturing share of total exports at the beginning of the episode

$\triangle T O T$ : Change in net export price (rolling weights) between 3-year average pre-episode and average during episode

$\triangle M a n \_X$ : change in manufacturing share of total exports between 3-year averages pre-episode and post-episode

$\triangle M T \_H T$ : change in medium- and high-tech share of total exports between 3-year averages pre-episode and post-episode

$\triangle M a n \_M$ : change in manufactures share of total imports between 3-year averages pre-episode and post-episode

$\triangle E C I$ : change in ECI between 3-year averages pre-episode and post-episode

$\triangle E X P Y$ Change: change in EXPY between 3-year averages pre-episode and post-episode

$\triangle$ Theil: change in Theil index between 3 -year averages pre-episode and post-episode 


\section{Indonesia}

Indonesia experienced all three episodes (1970, 1990, and 2005) at relatively low levels of per capita GDP, and as an economy where manufactures are less than 50\% of total merchandise exports. Major commodity exports include crude oil, natural gas, coal, and minerals. The first and third episodes, which were accompanied by substantial positive terms of trade shocks ended in essentially unchanged (in the case of the first), or significantly lower (in the case of the third) shares of manufactured exports. Thus, positive terms of trade shocks involving rising primary commodity prices were accompanied by higher investment but lower export shares of manufactures.

The second episode, which was the only one that did not occur during a period of rising terms of trade, was also the only episode that led to diversification (the Theil index declined by 1.3 percentage points) and increasing economic complexity. Moreover, it is the only episode that saw a rise in the share of manufactured exports and a significant shift toward medium- and high-tech manufactures. The effects of the primary commodity shock of the early 2000s is visible in the declining proportion of medium- and high-tech exports and the dramatic decline in the EXPY index. This is consistent with the Dutch disease pattern whereby countries that mainly export primary commodities and experience positive terms of trade shocks are likely to see non-primary tradable sectors stagnate or contract.

\section{Peru}

Peru experienced two episodes (1993 and 2004) at relatively low levels of per capita GDP. At the beginning of the episodes, manufactures were less than a quarter of total merchandise exports. Major commodity exports include minerals (copper, gold and zinc) as well as some textiles.

The first episode, which did not occur during a period of rising terms of trade, led to some diversification and decreasing economic complexity and there was some expansion of manufactured exports. During the late 1980s Peru suffered from a hyperinflation in the context of the so-called Latin-American lost decade. The recovery during the 1990s 
included the combination of macroeconomic stabilization with structural reforms and liberalization. The episode took place during a period of large capital inflows and real exchange rate appreciation.

The second episode was accompanied by a substantial positive terms of trade shock which led to specialization but higher complexity. The positive terms of trade shock involved rising primary commodity prices and was accompanied by higher investment but lower export shares of manufactures.

\section{Turkey}

Turkey experienced three episodes $(1964,1983,2003)$, all of them ending in diversification or no significant change; only during the first episode was there an increase in complexity. The second episode, accompanied by a global decline in primary commodity prices, led to the largest increase in the share of manufactures and, within manufactures, to the largest increase in the share of medium and high technology exports.

The terms of trade did not seem to play an important role, as they increase during the second episode, but they decrease during the third, without any noticeable trace on the exports basket. Turkey was already exporting a large share of manufactured goods and it does not have much potential to produce natural resources.

\section{Uganda}

Uganda experienced three episodes (1965, 1995, and 2003), starting from a low level of income and a small share of exports of manufactures (which were almost zero during the first episode in 1965, and slightly above $10 \%$ of total exports during the third one). Interestingly, terms of trade did not seem to play an important role, even though the Ugandan export basket includes mainly coffee, cotton, tobacco, tea, bananas, maize and beans (which is a relatively diversify basket for a commodity exporter). However, the third episode takes place right after the second one, which takes place with declining terms of trade. 
Overall, the Uganda export sector has become more diverse and complex during the second and third episodes, which is an atypical outcome for a commodity exporter. The second episode took place after a structural adjustment process which reduced inflation and reorganized the public sector accounts, the liberalization of domestic and foreign trade, and with substantial support in the form of aid and loans from multilateral financial institutions, and these may have played a role in the outcomes.

To sum up this section, our brief case studies suggest a few broad themes. The first is that positive terms of trade shocks in primary exporters can lead to investment surges that do not result in structural change in terms of diversification or increasing complexity. Second, investment episodes at different levels of income may have different outcomes in terms of complexity and diversification. ${ }^{7}$ Third, complexity and diversification often move in opposite directions. These factors along with our small sample size help at least partly explain why our statistical tests fail to capture robust trends in structural change following investment episodes.

\section{Conclusions}

Diversification of economic structures typically requires capital investment, especially in developing countries. Since less developed countries have to import much of their capital goods and sophisticated industrial inputs, episodes of high investment can create problems for the balance of payments. We find some support for this concern that has been traditionally highlighted by the structuralist literature.

One would also expect periods of atypically high investment to result in increased economic complexity and diversification of export structure. Focusing on a sample of 143 investment surges, we fail to find statistically robust econometric results consistent with these expectations. Apart from the low statistical power of our tests, this may be due to

\footnotetext{
${ }^{7}$ We discussed South Korea here but a similar pattern of early diversification and later specialization emerges in the case of Taiwan, which had two episodes, one in 1960 and the other in 1988, and is the only other relatively large economy that went from being a low income country to a high income industrialized one during our sample period, and experienced episodes at different stages of its development.
} 
several other reasons, including the initial conditions, differences in the nature of changes that lead to investment accelerations, and the fact that export diversification and economic complexity do not always move in the same direction. Moreover, episodes of sustained high investment may not be sufficiently different in their effects on macro variables than less dramatic periods of significant investment. Our preliminary investigation employing less formal approaches suggests that some of these possibilities deserve further attention and that a more comprehensive research design should incorporate the heterogeneity of investment episodes as they interact with diverse economic structures. High investment may often be a necessary but not sufficient condition for structural change.

\section{References}

Cadot, O., Carrere, C., \& Strauss-Kahn, V. (2011). Export Diversification: What's behind the Hump? The Review of Economics and Statistics, 93(2), 590-605.

Hausmann, R., Pritchett, L., \& Rodrik, D. (2005). Growth Accelerations. Journal of Economic Growth, 10(4), 303-329.

Hausmann, R., Hwang, J., \& Rodrik, D. (2007). What You Export Matters. Journal of Economic Growth, 12(1), 1-25.

Hidalgo, C. A., \& Hausmann, R. (2009). The building blocks of economic complexity. Proceedings of the National Academy of Sciences, 10570-10575.

Iacovone, L., \& Javorcik, B. (2008). Multi-product exporters: Diversification and microlevel dynamics. World Bank Policy Research Working Paper 4723.

Imbs, J., \& Wacziarg, R. (2003). Stages of Diversification. American Economic Review, 93(1), 63-86.

Jordà, Ò. (2005). Estimation and Inference of Impulse Responses by Local Projections. American Economic Review, 95(1), 161-182. 
Kaminsky, G., Reinhart, C., \& Végh, C. (2004). When It Rains, It Pours: Procyclical Capital Flows and Macroeconomic Policies. NBER Macroeconomics Annual, 19, 11-53.

Lall, S. (2000). The Technological Structure and Performance of Developing Country Manufactured Exports, 1985-1998. Oxford Development Studies, 28(3), 337-369.

Libman, E., Montecino, J., \& Razmi, A. (2019). Sustained Investment Surges. Oxford Economic Papers, 71(4), 1071-1095.

Perilla-Jimenez, J. R. (2019). Mainstream and evolutionary views of technology, economic growth and catching up. Journal of Evolutionary Economics, 29(3), 823-852.

Ros, J. (2013). Rethinking Economic Development, Growth, and Institutions. Oxford University Press. 